\title{
Trends in Medicaid fee-for-service outpatient drug utilization, expenditures, and pharmacy reimbursement rates (2010-2012)
}

\author{
Bander Balkhi $^{1 *}$, Abdulrahman Alshehri ${ }^{2}$ \\ ${ }^{1}$ Pharmacoeconomic Research Unit, King Saud University, College of Pharmacy, Riyadh, Saudi Arabia, ${ }^{2}$ Security Forces \\ Hospital Program, Riyadh, Saudi Arabia
}

*For correspondence: Email: bbalkhi@ksu.edu.sa

Sent for review: 20 October 2017

Revised accepted: 15 January 2018

\begin{abstract}
Purpose: To assess drug utilization and expenditure trends in Medicaid fee-for-service program during the period 2010 - 2012 in the United States of America.

Methods: A retrospective, descriptive analysis of the trend in drug utilization and expenditures in the Medicaid fee-for-service (FFS) program was performed using Medicaid state drug utilization data provided by Centers for Medicare and Medicaid Services (CMS) in the United States. Descriptive analyses were performed for all variables in the study. Association between prescription-drug utilization and reimbursement rate was examined using a linear regression model.

Results: The results indicate that prescription-drug utilization of Medicaid FFS program decreased by $20 \%$ during the period (2010 - 2012) as also drug expenditure during the same period. Although constituting nearly $70 \%$ and about $75 \%$ of the total drug utilization in 2010 and 2012, respectively, generics represent only around $18 \%$ of the total drug expenditures. No statistically significant association was found between total expenditures and the reimbursement rate.

Conclusion: FFS Medicaid drug expenditures decreased from 2010 to 2012 mainly due to a reduction in the total number of prescriptions as also the prices of generic drugs. Thus, higher utilization of generic drugs may offer substantial savings to Medicaid programs at the state level.
\end{abstract}

Keywords: Fee-for-service programs, Medicaid program, Generic drug utilization; Branded drugs, Patient Protection and Affordable Care Act

\footnotetext{
This is an Open Access article that uses a funding model which does not charge readers or their institutions for access and distributed under the terms of the Creative Commons Attribution License (http://creativecommons.org/licenses/by/4.0) and the Budapest Open Access Initiative (http://www.budapestopenaccessinitiative.org/read), which permit unrestricted use, distribution, and reproduction in any medium, provided the original work is properly credited.
}

Tropical Journal of Pharmaceutical Research is indexed by Science Citation Index (SciSearch), Scopus, International Pharmaceutical Abstract, Chemical Abstracts, Embase, Index Copernicus, EBSCO, African Index Medicus, JournalSeek, Journal Citation Reports/Science Edition, Directory of Open Access Journals (DOAJ), African Journal Online, Bioline International, Open-J-Gate and Pharmacy Abstracts

\section{INTRODUCTION}

Medicaid is the largest healthcare insurance in the nation, and it is the key source of prescription medications for low-income Americans. According to a recent report by Kaiser, over 60 million Americans were covered under Medicaid [1]. Patient Protection and Affordable Care Act (ACA) expanded the eligibility of the Medicaid program to millions of Americans $[2,3]$. Under the new healthcare reform, the prescription drugs paid by Medicaid will be significantly increase. 
Rising prescriptions drug costs are a challenge for Medicaid programs, and cost-containment strategies are needed [4].

Medicaid programs have implemented a variety of policies aiming to control drug costs [5]. State Medicaid programs use different criteria to set the reimbursement for branded and generic drugs to control their spending on prescription medication $[5,6]$. The simplest strategy used is an increase in generic drug utilization. After the patent of a branded drug expires, a generic version of the drug will be available at a much lower cost [7]. Prices of generic drugs will continue to decline as more firms enter the generics market, which is known as a multidrug source [8]. Taking advantage of the prices of generic drugs can have a potential impact on expenses [9]. Using a low-cost, generic alternative of a branded drug when available provides substantial savings on medication expenditure in state Medicaid program $[9,10]$.

Medicaid programs reimburse pharmacies for drugs prescribed to eligible beneficiaries [11]. Reimbursement, generic substitution, and dispensing fee vary among the states, and each state sets its own policies to control drug spending [12]. Utilizing more generic drugs and setting appropriate pharmacy reimbursement rates could result in substantial savings to the Medicaid program [13].

The differences among the states in criteria for reimbursement and dispensing fee amount highlights the need for a better understanding of the factors that affect drug utilization and expenditures. This study assesses drug utilization, expenditures, and reimbursement rate in Medicaid FFS program for the period 20102012.

\section{METHODS}

A retrospective, descriptive analysis was performed on state-level Medicaid data provided by the Centers for Medicare and Medicaid Services (CMS) to examine the trend in drug utilization and expenditure under the program [14]. Pharmacy reimbursement rate includes both ingredient cost and dispensing fees. Each state's annual report includes information about the total number of claims, number of generics and branded drug claims, utilization percentage of both types of drugs, and total amount paid by each state for the two types. In addition, we estimated the average expenditure of generic and branded drugs as well as their average prices paid by Medicaid [15].
Fee-for-service Medicaid prescription utilization from 2010 to 2012 for 42 states was included in this study. Eight states were excluded because they did not report annual drug utilization report to CMS during the period of 2010 to 2011 .

\section{Data analysis}

All variables in the study were descriptively analyzed. Continuous variables were calculated as confidence intervals (95\%). The association between ingredient cost, dispensing fees, and drug utilization was examined using a linear regression model. The US consumer price index (CPI) was used to adjust price levels to 2012 to account for inflation [15]. The significance level for variables in this study was set at $p<0.05$. All statistical analyses were performed using SPSS version 21 (SPSS Inc., Chicago, USA).

\section{RESULTS}

From 2010 to 2012, FFS Medicaid expenditures in the states studied fell from $\$ 23.0$ billion to $\$ 18.7$ billion, that is, a $14.9 \%$ decrease. Medicaid fee-for-service spent about $\$ 21.4$ billion out of $\$ 23$ billion on drug ingredient cost in 2010, which was nearly $93 \%$ of all Medicaid pharmacy spending with the remaining $7 \%$ being spent on dispensing fee. The spending on ingredient cost and dispensing fee stood at $94 \%$ and $6 \%$, respectively of all Medicaid pharmacy spending in 2012.

Our analysis demonstrated that the total prescription-drug utilization in Medicaid program decreased by nearly $20 \%$ from 351.2 million in 2010 to 281.4 million claims in 2012. Approximately $70.6 \%$ of all Medicaid prescriptions in 2010 were dispensed using generic drugs, and this figure reached $75.4 \%$ by 2012 (Table 1).

Table 1: Medicaid fee-for-service drug utilization and expenditures (2010-2012)

\begin{tabular}{lccc}
\hline Variable & \multicolumn{3}{c}{ Year } \\
\cline { 2 - 4 } & $\mathbf{2 0 1 0}$ & $\mathbf{2 0 1 1}$ & $\mathbf{2 0 1 2}$ \\
\hline $\begin{array}{l}\text { Claims } \\
\text { (million) }\end{array}$ & 351.2 & 333.3 & 253.7 \\
$\quad$ Generics (\%) & 71 & 72 & 75 \\
$\quad$ Branded (\%) & 29 & 28 & 25 \\
Expenditure (\$ & 23.5 & 25.0 & 18.6 \\
billion) & & & \\
$\quad$ Generics (\%) & 18 & 17 & 17 \\
Branded (\%) & 82 & 83 & 83 \\
\hline
\end{tabular}

Generic drug utilization in Medicaid programs varied from $64 \%$ (Connecticut) to $84 \%$ (Hawaii) in 2010, and the corresponding rates were $67 \%$ and $88 \%$, respectively in 2012 , with eight states 
(Kansas, Kentucky, Nebraska, Virginia, Georgia, Massachusetts, Hawaii, and Rhode Island) reporting more than $80 \%$. On the other hand, three states (Connecticut, Texas, and Florida) reported generics utilization at less than $70 \%$ of total drug utilization (Figure 1).

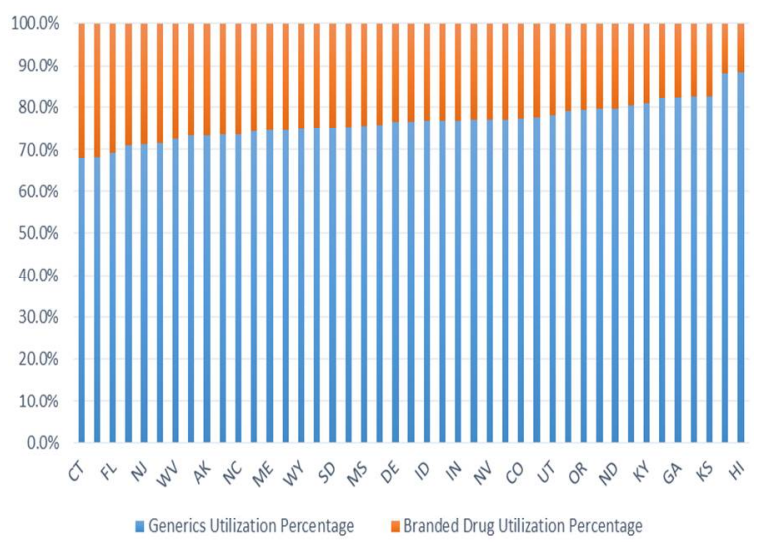

Figure 1: Medicaid fee-for-service drug utilization by state (2012)

States with higher generic drug utilization than the national average saved a significant amount on drug expenditure as the share of generic drugs varied from $15 \%$ to $27 \%$. Expenditure on generic drugs accounted for only $17.9 \%$ and $18.0 \%$ of total Medicaid drug expenditure in 2010 and 2012, respectively (Figure 2). The average generic drugs reimbursement in 2010 was $\$ 17.89$ (95\% Cl, $\$ 16.63$ - \$19.14) which decreased in 2012 to $\$ 16.91(95 \% \mathrm{Cl}, \$ 14.48$ $\$ 19.34$ ), which is nearly 12 times lower than the \$197.34 (95\% Cl, \$184.74 - \$209.94) paid on average for branded drugs prescription. In 2012, the average reimbursement of branded drugs prescription increased to $\$ 235.93(95 \% \mathrm{Cl}$, \$218.07 - \$253.79) (Figure 3).

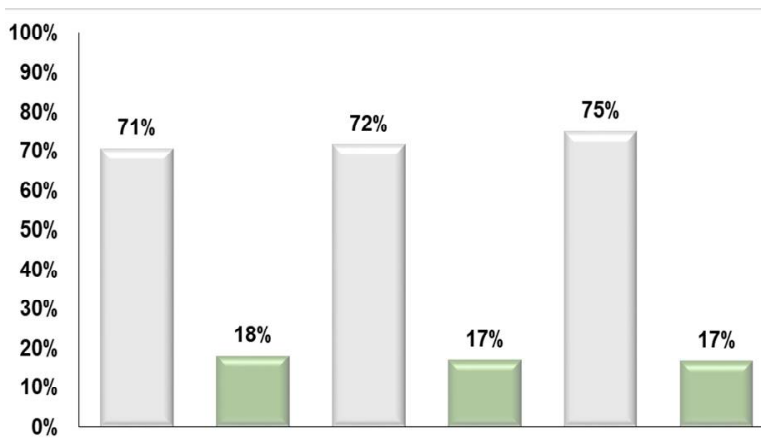

Figure 2: Medicaid fee-for-service percentage of generic drugs utilization and expenditures (2010 2012)

State dispensing fees for branded drug ranged from $\$ 1.75$ and $\$ 1.80$ in New Hampshire and Ohio to a high of $\$ 11.51$ - $\$ 15.11$ in Idaho depending on total annual prescription volume.
Idaho and Oregon were among the states that used the Average Acquisition Cost (AAC) method for reimbursement, and their dispensing fee were the highest across the state. The national average pharmacy dispensing fee for generic drugs was $\$ 4.34 \pm \$ 1.24$ in 2010 and increased in 2012 to $\$ 4.60 \pm \$ 2.56$ while the average dispensing fee for brand drugs increased from $\$ 4.10 \pm \$ 1.19$ to $\$ 4.38 \pm \$ 2.58$ during the same period.

We found no statistically significant association between total number of claims/expenditures and pharmacy reimbursement rate (ingredient cost or dispensing fee).

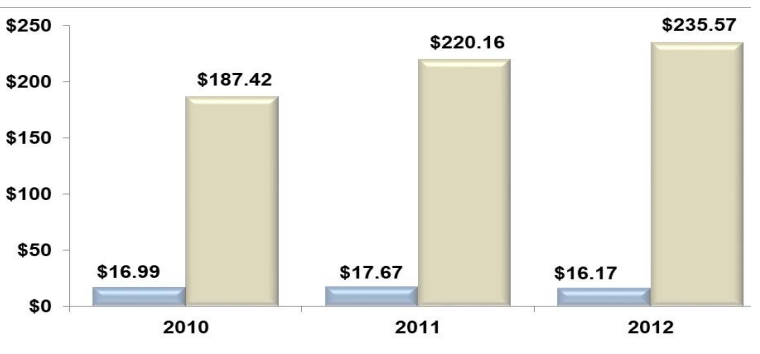

Figure 3: Medicaid fee-for-service average reimbursement per claim (2010 - 2012)

\section{DISCUSSION}

Medicaid program spent nearly $\$ 23$ billion dollar on fee-for-service (FFS) prescription drugs for more than 351 million prescriptions. The number of prescription drugs paid by Medicaid declined to 253 million prescriptions in 2012 with a total cost of $\$ 18$ billion dollars. From 2010 to 2012 , generic utilization reached $75 \%$ of all prescriptions paid by Medicaid. Utilization of generic drugs varies across states due to differences in states policies for reimbursement of prescription drugs, a possible variation in prescribing patterns, and differences in disease prevalence [16]. States promote dispensing of generic drugs as an approach to contain the high drug cost in their programs. Medicaid saving from generic drugs could be greater as the patents of top branded drugs expire. Once a lowcost generic drug becomes available, it is critical that Medicaid does not reimburse a branded drug [17].

According to our analysis, the average price of a branded drug at $\$ 197.3$ was about nine times higher than that of generic drugs, which stood at $\$ 17.89$ in 2010. The average price Medicaid paid for branded drugs increased to $\$ 235.9$, about 14 times higher than that paid for the generic alternatives in 2012. Medicaid saved an average $\$ 220$ when the pharmacies dispensed a low-cost generic drug instead of a branded one. Although 
branded drugs represented only $25 \%$ of the total prescription, it accounted for more than $83 \%$ of the total cost of prescription drugs under Medicaid. The remaining $75 \%$ prescriptions were dispensed using a low-cost generic drug, and this constituted only $17 \%$ of Medicaid prescription drug spending. This indicates that Medicaid could achieve substantial savings by encouraging the use of generic drugs.

The number of prescription drugs are expected to increase in 2014 due to the new healthcare reform in which millions of uninsured or inadequately insured Americans will be covered under the Medicaid program [18]. This upcoming expansion will have a significant impact on Medicaid's expenditure on prescription drugs and utilization [19]. This demonstrates that managing the growth in prescription spending is important for each Medicaid program. States have developed numerous strategies to contain the high drug costs. They have set a different reimbursement rate and dispensing fee for branded and generic drug $[20,21]$. They also seek to promote use of the generic version of drugs if available by incentivizing to pharmacies to dispense such a version $[13,22]$. Other strategies include requiring prior authorization for branded drugs, setting higher copayment for branded drugs, and mandating generic substitution and a preferred drugs list [4].

Our analysis demonstrates a substantial difference in drug utilization rates, ingredient costs, dispensing fees, and reimbursement rate in the Medicaid programs. These differences indicate the opportunities available for encouraging the prescription payment in the state Medicaid fee-for-service system [23]. Medicaid policies for drug reimbursement have a significant impact on promoting the dispensing of generic drugs [24]. Increased reimbursement for generic drugs could incentivize pharmacies to dispense such drugs and increase their utilization thus yielding additional savings on Medicaid FFS programs.

\section{Limitations of the study}

This study has some limitations. Characteristics and clinical information of the Medicaid population were not available in Medicaid pharmacy claims data that we used in this study. Accordingly, we were unable to assess the impact of utilization and expenditure on Medicaid beneficiaries' outcomes. Higher expenditures could be associated with better treatment outcomes. Another limitation is that the total drug expenditure could be overestimated as data provided by CMS did not include information about drug manufacturer rebates, which could affect the total drug cost paid by Medicaid program. Finally, utilization and expenditures of Medicaid FFS program presented in this study cannot be generalized to other US health markets.

\section{CONCLUSION}

This study found variations in generic utilization across states between 2010 and 2012 . Reduction in the total volume of prescription drugs as well as prices of generic drugs in the period 2010 - 2012 contributed to lower pharmacy expenditures. On average, $75 \%$ of all prescriptions paid by Medicaid are generics. Nearly $50 \%$ of the states show generics utilization in Medicaid at lower than the national average of $75 \%$. These findings suggest that additional savings can be achieved by encouraging and promoting generic drugs use in Medicaid programs, especially in states with lower generics utilization rate.

To improve the level of generic drugs utilization, Medicaid programs should adequately reimburse pharmacies to encourage them to dispense such drugs. Variation in reimbursement rate (dispensing fees and ingredient costs) across different FFS Medicaid programs are independent of total volume of prescription. Future studies that identify and evaluate the dispensing pattern of branded drugs when a lowcost generic is available might disclose the potential savings from the utilization of generic drugs.

\section{DECLARATIONS}

\section{Acknowledgement}

The authors would like to thank College of Pharmacy Research Center and Deanship of Scientific Research, King Saud University (Riyadh, Saudi Arabia) for supporting this research.

\section{Conflict of interest}

No conflict of interest is associated with this work

\section{Contribution of authors}

The authors declare that this work was done by the authors named in this article, and all liabilities pertaining to claims relating to the content of this article will be borne by them. 


\section{REFERENCES}

1. Kaiser Family Foundation. Medicaid Enrollment: December 2009 Data Snapshot. Available from: http://assets.bizjournals.com/cms_media/southflorida/pd f/Kaiser\%20Medicaid\%20report.pdf. Accessed December 22, 2016.

2. The Patient Protection and Affordable Care Act. Pub $L$ No. 111-148. 124 Stat 119 through 124 Stat 1025.

3. Sommers BD, Epstein AM. Medicaid expansion-the soft underbelly of health care reform? N Engl J Med 2010; 363: 2085-2087.

4. Hoadley J. Cost containment strategies for prescription drugs: assessing the evidence in the literature. Henry J. Kaiser Family Foundation; 2005.

5. Orentlicher D. Cost Containment and the Patient Protection and Affordable Care Act. FIU L. Rev. 2010; 6: 67.

6. Cunningham PJ. Medicaid cost containment and access to prescription drugs. Health Affairs 2005; 24(3): 780789.

7. Brill A. Overspending on multi-source drugs in Medicaid. AEI Health Policy Studies Working Paper; 2011.

8. Wiggins $S N$, Maness R. Price Competition in Pharmaceuticals: The Case of Anti-infectives. Economic Inquiry 2004; 42(2): 247-263.

9. Fischer MA, Avorn J. Potential savings from increased use of generic drugs in the elderly: what the experience of Medicaid and other insurance programs means for a Medicare drug benefit. Pharmacoepidemiology and Drug Safety 2004; 13(4): 207-214.

10. Andersson K, Bergström G, Petzold MG, Carlsten A. Impact of a generic substitution reform on patients' and society's expenditure for pharmaceuticals. Health Policy 2007; 81(2): 376-384

11. Berndt ER, Newhouse JP. Pricing and reimbursement in US pharmaceutical markets. No. w16297. National Bureau of Economic Research; 2010.

12. Shrank WH, Choudhry NK, Agnew-Blais J, Federman $A D$, Liberman JN, Liu J, Kesselheim AS, Brookhart MA, Fischer MA. State generic substitution laws can lower drug outlays under Medicaid. Health Affairs 2010; 29(7):1383-1390.

13. Fischer MA, Avorn J. Economic consequences of underuse of generic drugs: evidence from Medicaid and implications for prescription drug benefit plans. Health Serv Res 2003; 38(4): 1051-1064.

14. Centers for Medicare and Medicaid Services. State drug utilization data. 2012. Available from: https://www.medicaid.gov/medicaid-chip-programinformation/by-topics/benefits/prescriptiondrugs/medicaid-drug-programs-data-andresources.html. Accessed Dec 22, 2016.

15. Balkhi B, Alshehri A, Szeinbach SL, Seoane-Vazquez $E$. Trends in Medicaid fee-for-service outpatient drug utilization, expenditures and pharmacy reimbursement rates (2010-2012). Value in Health 2014; 17(3): A16-17.

16. Abramson, RG, Harrington CA, Missmar R, Li SP, Mendelson DN. Generic drug cost containment in Medicaid: lessons from five state MAC programs. Health Care Financ Rev 2004; 25(3): 25.

17. Regan TL. Generic entry, price competition, and market segmentation in the prescription drug market. International Journal of Industrial Organization 2008; (26) 4: 930-948

18. Sommers $B D$, Musco T, Finegold K, Gunja MZ, Burke A, McDowell AM. Health reform and changes in health insurance coverage in 2014. New Engl J Med 2014; 371(9): 867-874.

19. Sisko AM, Keehan SP, Cuckler GA, Madison AJ, Smith $S D$, Wolfe CJ, Stone DA, Lizonitz JM, Poisal JA. National health expenditure projections, 2013-23: faster growth expected with expanded coverage and improving economy. Health Affairs 2014; 10-1377.

20. Cunningham PJ. Medicaid cost containment and access to prescription drugs. Health Affairs 2005; 24(3): 780789.

21. Moore WJ, Newman RJ. Drug formulary restrictions as a cost-containment policy in Medicaid programs. The Journal of Law \& Economics 1993; 36(1): 71-97.

22. Kelton CML, Lenisa VC, Kreling DH. State Medicaid programs missed $\$ 220$ million in uncaptured savings as generic fluoxetine came to market, 2001-05. Health Affairs 2013; 32(7): 1204-1211.

23. Coster, J. Changes in Medicaid Reimbursement: Implications for Generic Manufacturers and Pharmacies. US Pharm 2011; 36(6): 12-20.

24. Kelton CML, Chang LV, Guo JJ, Yu Y, Berry EA, Bian B, Heaton PC. Firm-and Drug-Specific Patterns of Generic Drug Payments by US Medicaid Programs: 1991-2008. Appl Health Econs Health Policy 2014; 12(2): 165-177. 